\title{
Research Skills in Primary School Students Formation: Developmental and Competence Impact
}

\author{
Aigul M. Beisenbayeva ${ }^{1, \#, *}$, Saltanat K. Abildina ${ }^{1, \#}$, Saltanat A. Feizuldayeva ${ }^{2, \#,}$ \\ Kamshat B. Kopbalina ${ }^{1, \#}$ and Zhanargul K. Kurmangaliyeva ${ }^{3, \#}$ \\ ${ }^{1}$ Karaganda State University named after E.A. Buketov, Karaganda, Republic of Kazakhstan \\ ${ }^{2}$ Zhetysu State University named after I. Zhansugurov, Taldykurgan, Republic of Kazakhstan \\ ${ }^{3}$ Turan-Astana University, Nur-Sultan, Republic of Kazakhstan
}

\begin{abstract}
Objective: The level of research skills of children with inclusion depends on the teacher's research competencies. To develop them, a future teacher must constantly conduct research and practical work in his own learning process.

Background: The formation of research competence in primary school children with disorders is formed on the basis of a common desire for knowledge of the world, due to age-related characteristics and social conditions of education. The task of a teacher in this vein is not only to structure the cognitive interest of younger students but also to integrate educational research competence into the age group.

Method: In preparing the study, students were required to deeply analyse information regarding the state of the issue, a comparative description of various modelling options and research methods, an analysis of their advantages, disadvantages, and the choice of a model and research method that would be adequate to the assigned tasks.

Results: Future teachers' willingness to present the teaching material is considered, and also the willingness to raise discussion questions and thus form additional research material. The authors of the article show that such competence is formed in the process of formation of general research competence and can be expressed in a number of definitions
\end{abstract} that require additional training of a future teacher.

Conclusion: There is a need to form research competency directly with teachers, who shape the future research qualities of "special" schoolchildren, which in turn forms the future of a scientific nature.

Keywords: Cultural mechanism, design and research activities, research competence, reproductive and heuristic levels of students, creative problem-solving.

\section{INTRODUCTION}

The basis of compensation for the reasons for the lag in educational activities lies in research activities. It is essentially multifunctional, i.e., along with the functions of training and development, priority should be compensation and rehabilitation of student deficiencies, which can be realised if the following conditions are met: -variability of training forms and methods should be based on individual and personality characteristics and resources of students; there should be a reliance on the special educational needs of this category of students, ensuring effective socialisation. Therefore, the modern professional training of teachers educating children with mental retardation (MR) should be aimed at forming future specialists with relevant competencies that meet future needs. In the training process, new skills should be actively formed - the ability to adapt and find oneself in new conditions, the

*Address correspondence to this author at the Karaganda State University named after E.A. Buketov, Karaganda, Republic of Kazakhstan; Tel: +8(7212) 356398; E-mail: a-beisenbayeva4915@tanu.pro

\#These authors are equally contributed. ability to independently collect information, analyse, generalise and transfer to others, and master new technologies [1]. An adequate response to the challenges of the time is the focus of the training of future teachers to the formation of research competence. It is necessary to turn to the analysis of the basic concepts of this problem. In the context of research, research activity is conceptual, which is defined as a cultural mechanism for the development of science, serving as a means of active search, building knowledge, and the formation of new experience. It is worth noting that in the modern world, research as a way of mastering reality is losing its exclusive membership in the field of science [2]. At the same time, research as a tool for mastering reality can occupy an important place in modern, inclusive education, since it solves the problem of developing new approaches for teaching children with MR based not on the assimilation of ready-made knowledge, but on the methods of obtaining it. This becomes especially relevant in the context of a rapid increase in the total knowledge of humanity and the need for each person to learn new specialities, specialisations and activities [3]. Modern requirements for higher education primarily 
pose the problem of forming a teacher-researcher before pedagogical universities. Only a teacher with the willingness and ability to conduct research activities can work in the modern conditions of educational integration, in the context of the changing contingent of students in special (correctional) schools and mass educational institutions. Only a special education teacher of a creative nature is able to achieve the main goal of special education for all children with special educational opportunities - introducing a child into the culture.

The formation of professional competence in a student preparing to work with children with special psychophysical development, in particular, with mental retardation, is impossible without arousing interest in the profession and instilling research skills. One of the most important forms designed to accomplish the task is preparing student academic research and research projects: essays, term papers, presentations at seminars and scientific conferences, abstracts of reading reports $[4,5]$. The most important and necessary condition for the fruitful completion of such work is the interconnection of educational research and research work of future special education teachers, who in the educational process should be closely related and aimed at the formation of students' methodological literacy. The study's objective is to determine the level of research skills of future teachers who will work with children with mental retardation (MR). Also, during the study, it is necessary to calculate the impact of their research competencies on the development of research skills in children with MR.

\section{MATERIALS AND METHODS}

In preparing the study, students were required to deeply analyse information regarding the state of the issue, a comparative description of various modelling options and research methods, an analysis of their advantages, disadvantages, and the choice of a model and research method that would be adequate to the assigned tasks. To conduct this study, methods such as analysis, generalisation, comparison, experiment, questioning, and data collection were used. To study the potential for developing research competencies among future teachers who will teach children with MR, the authors studied the theoretical work of scientists, methods for developing research skills during the educational process in children with mental retardation, and future teachers. The presence of such techniques in the education program and their effectiveness were analysed. In order to study the reason for the formation of future research skills of teachers and methods for their development, a formative experiment was conducted. It was attended by 50 students of the Educational studies faculty of $2^{\text {nd }}$ and $3^{\text {rd }}$ years. As experts evaluating the results of the experiment, 8 teachers of this faculty were selected. The experiment took place in several stages.

At the evaluation stage of the formative experiment, students conducted research among schoolchildren with MR aged 10 to 12 years, studying in the correctional class of a comprehensive school, in order to study their preferences in research. The experiment involved 40 children with mental retardation. The study was conducted with the participation of pedagogues and under the supervision of teachers of the educational institution. The study was conducted on the basis of interviews of students and work with pedagogical documentation. The task of future teachers was to draw up questions for the questionnaire and conduct a questionnaire directly. The next step was to collect the information received and summarise the survey results by students of the Educational studies faculty. Their task was to identify the presence and level of research abilities in children with MR. The results obtained at the last stage were transferred to experts who evaluated the formation of future teachers' research competence when working with students. The students' work was analysed, a conscious attitude to research activity, its effectiveness, and awareness of the interdependence of research competence and successful professional activities of future teachers were evaluated. Based on the results obtained, recommendations were developed that can help develop an educational program for future teachers to develop their research competence and the ability to effectively educate children with mental retardation.

\section{RESULTS}

At the final stage of the formative experiment, in order to determine the changes that occurred in the formation levels of the research competence of future teachers who are to educate children with mental retardation in the process of studying the subject area, re-diagnosis was carried out according to the methodology that was used at the ascertaining stage of the pedagogical experiment. Consider the results of the formedness of the research competence of future teachers in terms of the motivational value criterion at the ascertaining and final stages of the experiment. Quantitative data on the diagnosis of the formation 
Table 1: Formation Levels of Research Competence in Terms of the Motivational-Value Criterion "Presence of Positive Motivation for Research Activity" (in \%)

\begin{tabular}{|c|c|c|c|c|}
\hline \multirow{2}{*}{ Levels } & \multicolumn{2}{|c|}{ EG } & \multicolumn{2}{c|}{ CG } \\
\cline { 2 - 5 } & Ascertaining & Final & Ascertaining & Final \\
\hline \hline Adaptive & 84.37 & 23.44 & 86.06 & 60.66 \\
\hline Reproductive & 10.94 & 52.34 & 9.84 & 28.69 \\
\hline Heuristic & 4.69 & 24.22 & 4.10 & 10.65 \\
\hline
\end{tabular}

levels of the research competence of future teachers of schoolchildren with psycho-emotional disorders in terms of the motivational-value criterion "Presence of positive motivation for research activity" at the ascertaining and final stages of the experiment are presented in Table 1.

As can be seen from the table, $23.44 \%$ of the students from the EG (before there was $84.37 \%$ ) and $60.66 \%$ from the CG (before there was $86.06 \%$ of students) were at the adaptive level. At the reproductive level, $52.34 \%$ of students in the EG (before there were $10.94 \%$ ) and $28.69 \%$ were in the CG (before there were 9.84\%). A heuristic level was found in $24.22 \%$ of students in the EG (before there were $4.69 \%$ ) and $10.65 \%$ in the CG (before there was $4.10 \%)$. These tables show that the vast majority of students in the EG were at the reproductive and heuristic levels. Quantitative data on the diagnosis of the levels of formedness of the research competence of future teachers in terms of the motivational-value criterion "The need for research activities in the learning process" at the ascertaining and final stages of the experiment are presented in Table 2.

As can be seen from the table, $23.43 \%$ of EG students (there were $77.34 \%$ ) and $55.74 \%$ of the CG (there were80.33\%) were at the adaptive level. 53.13\% of the students from the EG (there were $18.75 \%$ ) and $31.15 \%$ from the CG (there were $16.39 \%$ ) were at the reproductive level.

A heuristic level was found in $23.44 \%$ of students in the EG (there were $3.91 \%$ ) and $13.11 \%$ in the CG (there were $3.28 \%$ ). These tables show that the vast majority of students in the EG were at the reproductive and heuristic levels. Quantitative data on the diagnosis of the formation levels of the research competence of future teachers of mentally ill children in terms of the motivational-value criterion "The presence of value orientations in research activity" at the ascertaining and final stages of the experiment are presented in Table 3.

As can be seen from the table, $22.66 \%$ of the students in the EG (there were $78.81 \%$ ) and $60.66 \%$ in

Table 2: Formation Levels of Research Competence in Terms of the Motivational-Value Criterion "The Need for Research Activity in the Learning Process" (in \%)

\begin{tabular}{|c|c|c|c|c|}
\hline \multirow{2}{*}{ Levels } & \multicolumn{2}{|c|}{ EG } & \multicolumn{2}{c|}{ CG } \\
\cline { 2 - 5 } & Ascertaining & Final & Ascertaining & Final \\
\hline \hline Adaptive & 77.34 & 23.43 & 80.33 & 55.74 \\
\hline Reproductive & 18.75 & 53.13 & 16.39 & 31.15 \\
\hline Heuristic & 3.91 & 23.44 & 3.28 & 13.11 \\
\hline
\end{tabular}

Table 3: Formation Levels of the Research Competence of Future Teachers of Mentally III Children in Terms of the Motivational-Value Criterion "The Presence of Value Orientations in Research Activity" (in \%)

\begin{tabular}{|c|c|c|c|c|}
\hline \multirow{2}{*}{ Levels } & \multicolumn{2}{|c|}{ EG } & \multicolumn{2}{c|}{ CG } \\
\cline { 2 - 5 } & Ascertaining & Final & 83.61 & 60.66 \\
\hline \hline Adaptive & 78.91 & 22.66 & 11.47 & 27.87 \\
\hline Reproductive & 15.62 & 50.78 & 4.92 & 11.47 \\
\hline Heuristic & 5.47 & 26.56 & & Final \\
\hline
\end{tabular}


Table 4: Formation Levels of the Research Competence in Terms of the Motivational-Value Criterion (in \%)

\begin{tabular}{|c|c|c|c|c|}
\hline \multirow{2}{*}{ Levels } & \multicolumn{2}{|c|}{ EG } & \multicolumn{2}{c|}{ CG } \\
\cline { 2 - 5 } & Ascertaining & Final & 84.43 & Final \\
\hline \hline Adaptive & 81.25 & 22.66 & 12.29 & 37.38 \\
\hline Reproductive & 14.06 & 53.12 & 3.28 & 9.79 \\
\hline Heuristic & 4.69 & 24.22 & \\
\hline
\end{tabular}

the CG (there were83.61\%) are at the adaptive level. At the reproductive level, there are $50.78 \%$ of the students in the EG (there were $15.62 \%$ ) and $27.87 \%$ (there were $11.47 \%$ ) in the CG. A heuristic level was found in $26.56 \%$ of students in the EG (there were $5.47 \%$ ) and $11.47 \%$ in the CG (there were $4.92 \%$ ). These tables show that the vast majority of students in the EG were at the reproductive and heuristic levels. The generalised results of the diagnosis of the formation levels of the research competence of future teachers of schoolchildren with psycho-emotional disorders in terms of the motivational-value criterion at the ascertaining and final stages of the experiment are presented in Table 4.

As can be seen from the table, $22.66 \%$ of EG students (there were $81.25 \%$ ) and $57.38 \%$ of the CG (there were84.43\%) were at the adaptive level. At the reproductive level, there are $53.12 \%$ of students in the
EG (there were $14.06 \%$ ) and $32.79 \%$ in the CG (there were $12.29 \%$ ). A heuristic level was found in $24.22 \%$ of students in the EG (there were $4.69 \%$ ) and $9.83 \%$ in the CG (there were $3.28 \%$ ). The data in the table show that the vast majority of students in the EG were at the reproductive and heuristic formation levels of research competence according to the specified criterion. The dynamics of the results of the formation levels of future teachers' research competence to educate children with mental retardation, according to the motivationalvalue criterion is presented in Figure 1.

The results indicate that during the formative stage of the pedagogical experiment, the level of development of the research competence of future teachers by the motivational-value criterion as a whole increased. Consider the results of the formedness of the research competence of future teachers of schoolchildren with pathogenesis condition in terms of

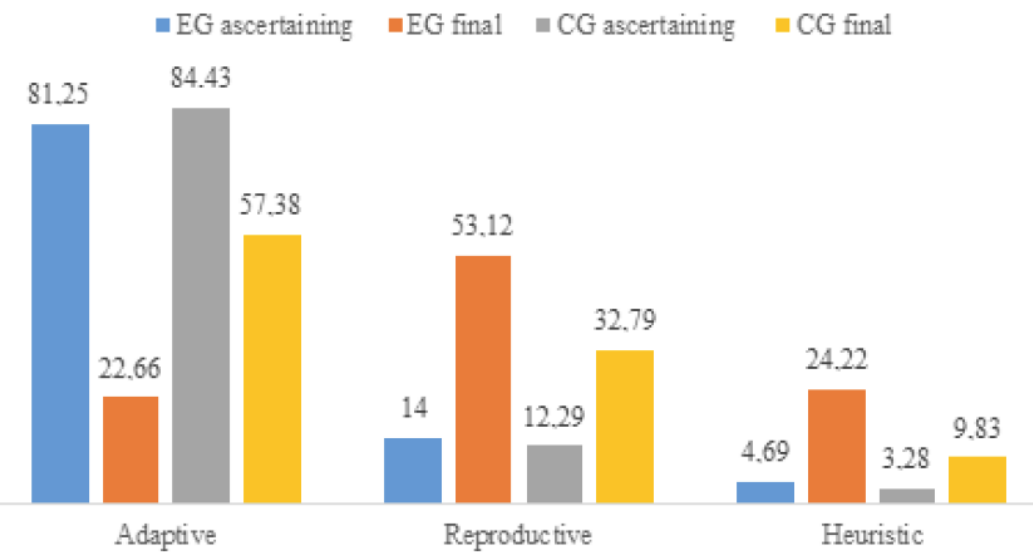

Figure 1: The dynamics of the results of the formation levels of the research competence in terms of the motivational-value criterion (in \%).

Table 5: Formation Levels of the Research Competence of Future Teachers in Terms of the Cognitive Indicator "Awareness in the Field of Research" (in \%)

\begin{tabular}{|c|c|c|c|c|}
\hline \multirow{2}{*}{} & \multicolumn{2}{|c|}{ EG } & \multicolumn{2}{c|}{ CG } \\
\cline { 2 - 5 } & Ascertaining & Final & 81.15 & Final \\
\hline \hline Adaptive & 76.56 & 25.00 & 12.29 & 27.87 \\
\hline Reproductive & 15.63 & 50.78 & 6.56 & 12.29 \\
\hline Heuristic & 7.81 & 24.22 & \multicolumn{2}{|c|}{} \\
\hline
\end{tabular}


Table 6: Formation Levels of the Research Competence in Terms of the Cognitive Criterion "Knowledge of Methods of Scientific Cognition" (in \%)

\begin{tabular}{|c|c|c|c|c|}
\hline & \multicolumn{2}{|c|}{ EG } & \multicolumn{2}{c|}{ CG } \\
\cline { 2 - 5 } & Ascertaining & Final & Ascertaining & Final \\
\hline \hline Adaptive & 79.69 & 27.34 & 79.51 & 55.74 \\
\hline Reproductive & 14.84 & 47.66 & 16.39 & 33.61 \\
\hline Heuristic & 5.47 & 25.00 & 4.10 & 10.65 \\
\hline
\end{tabular}

cognitive criteria at the ascertaining and final stages of the experiment. Quantitative data on the diagnosis of the formation levels of the research competence of future teachers in terms of the cognitive indicator "Awareness in the field of research" at the ascertaining and final stages of the experiment are presented in Table 5.

As can be seen from the table, at the adaptive level, $25.00 \%$ of students in the EG (there were $76.56 \%$ ) and $59.84 \%$ in the CG (before $-81.15 \%$ ). At the reproductive level, $50.78 \%$ of students in the EG (before $-15.63 \%$ ) and $27.87 \%$ in the CG (before $12.29 \%$ ). The heuristic level was found in $24.22 \%$ of students in the EG (before $-7.81 \%$ ) and $12.29 \%$ in the CG (before $-6.56 \%$ ). These tables show that the vast majority of students in the EG were at the reproductive and heuristic levels. Quantitative data on the diagnosis of the formation levels of the research competence of future teachers of schoolchildren with neuroses in terms of the cognitive criterion "Knowledge of methods of scientific cognition" at the ascertaining and final stages of the experiment are shown in Table 6.

As can be seen from the table, $27.34 \%$ of EG students (there were $79.69 \%$ ) and $55.74 \%$ of the CG (there were $79.51 \%$ ) are at the adaptive level. At the reproductive level, $47.66 \%$ of students in the EG (there were $14.84 \%$ ) and $33.61 \%$ in the CG (there were $16.39 \%$ ). A heuristic level of awareness was found in $25.00 \%$ of students in the EG (there were $5.47 \%$ ) and $10.65 \%$ in the CG (there were $4.10 \%$ ). These tables show that the vast majority of students in the EG were at the reproductive and heuristic levels. Quantitative data on the diagnosis of the formation levels of the research competence of future teachers of mentally ill children in terms of the cognitive criterion "Awareness in the field of scientific communication" at the ascertaining and final stages of the experiment are presented in Table 7.

As can be seen from the table, $24.22 \%$ of the students from the EG (there were $78.91 \%$ ) and $53.28 \%$ from the CG (there were $80.33 \%$ ) are at the adaptive level. At the reproductive level, there are $52.24 \%$ of the students in the EG (there were $14.84 \%$ ) and $31.97 \%$ in the CG (there were $13.93 \%$ ). The heuristic level of awareness was found in $23.44 \%$ of students in the EG (there were $6.25 \%$ ) and $14.75 \%$ in the CG (there were $5.74 \%$ ). These tables show that the vast majority of students in the EG were at the reproductive and heuristic levels. The generalised results of the diagnosis of the formation levels of the research competence of future teachers of schoolchildren with abnormal behaviour in terms of the cognitive criterion at the ascertaining and final stages of the experiment are presented in Table $\mathbf{8}$.

As can be seen from the table, $25.78 \%$ of the students in the EG are at the adaptive level of research competency by this criterion (there were $78.91 \%$ ). $50.78 \%$ - at the reproductive (there were $17.19 \%$ ). $23.44 \%$ - heuristic (there were $3.90 \%$ ). In the CG, the distribution is as follows: adaptive - in $54.92 \%$ (there were $78.91 \%$ ), reproductive - in $34.43 \%$ (there were $17.21 \%$ ), heuristic $-10.65 \%$ (there were $3.28 \%$ ) of students. The data in the table show that the vast majority of students in the EG were at the reproductive

Table 7: Formation Levels of the Research Competence in Terms of the Cognitive Criterion "Awareness in the Field of Scientific Communication" (in \%)

\begin{tabular}{|c|c|c|c|c|}
\hline \multirow{2}{*}{} & \multicolumn{2}{|c|}{ EG } & \multicolumn{2}{c|}{ CG } \\
\cline { 2 - 5 } & Ascertaining & Final & 80.33 & Final \\
\hline \hline Adaptive & 78.91 & 24.22 & 13.93 & 53.28 \\
\hline Reproductive & 14.84 & 52.34 & 5.74 & 14.97 \\
\hline Heuristic & 6.25 & 23.44 & \\
\hline
\end{tabular}


Table 8: Formation Levels of the Research Competence in Terms of the Cognitive Criterion (in \%)

\begin{tabular}{|c|c|c|c|c|}
\hline \multirow{2}{*}{} & \multicolumn{2}{|c|}{ EG } & \multicolumn{2}{c|}{ CG } \\
\cline { 2 - 5 } & Ascertaining & Final & 78.91 & Final \\
\hline \hline Adaptive & 78.91 & 25.78 & 17.21 & 34.92 \\
\hline Reproductive & 17.19 & 50.78 & 3.28 & 10.65 \\
\hline Heuristic & 3.90 & 23.44 & \\
\hline
\end{tabular}

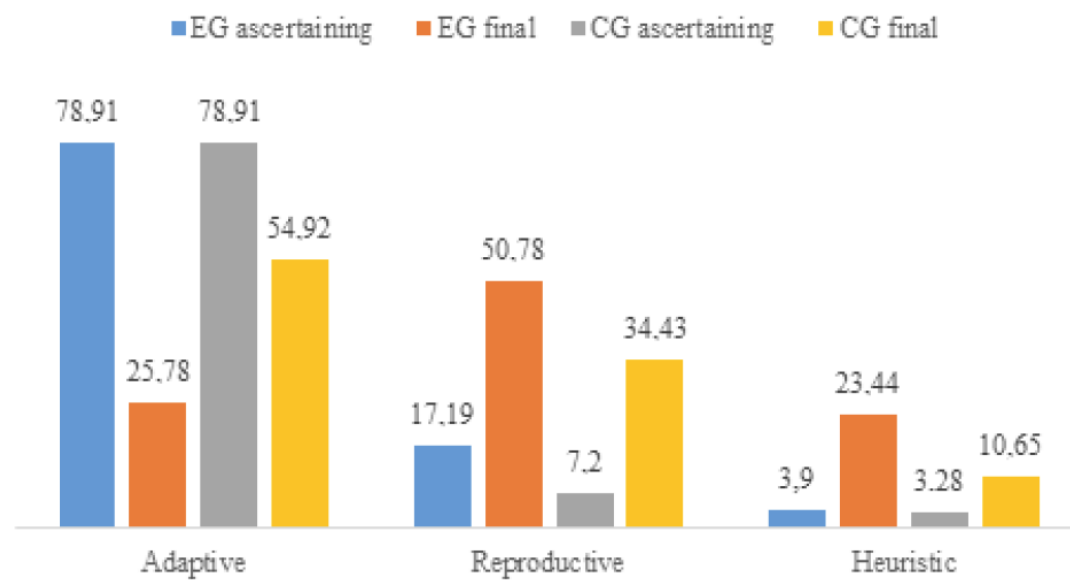

Figure 2: The dynamics of the results of the formation levels of the research competence in terms of the cognitive criterion at the ascertaining and final stages (in \%).

and heuristic formation levels of research competence according to the specified criterion. The dynamics of the results of the formation levels of the research competence of future teachers of schoolchildren with disabilities in terms of the cognitive criterion at the ascertaining and final stages of the experiment is clearly illustrated in Figure 2.

The results indicate that during the formative stage of the pedagogical experiment, the formedness level of the research competence of future teachers of schoolchildren with psycho-emotional disorders by the cognitive criterion as a whole increased.

\section{DISCUSSIONS}

In the conditions of the new educational paradigm, a modern elementary school needs a teacher who not only knows his discipline perfectly but also is able to create all the necessary psychological and pedagogical conditions for the development and self-development of the student's personality, its key competencies [6]. It should be noted that the formation of research competence is a complex educational and creative process. The presence and formation of research knowledge and skills are one of the brightest characteristics of the professional maturity level of a teacher, in this regard, of such scientists as V.I.
Andreev, L.M. Abolin, and others devoted their earlier works to the problems of the development of various aspects of the teacher's research competence and his activities. Their works showed the necessity to develop the research competence of a teacher in the process of professional activity and in the framework of advanced training [7]. However, the importance of educating research skills among future educators is not considered. In educational research, a student, through intellectual self-realisation, carries out socially significant actions (social adaptation, social and professional self-determination, etc.) [8]. Seeing in the process of professional training a system of targeted, desirable social needs conditions for the transfer of social experience, in the context of the proposed research, they are in tune with the position that, in the opinion of M. Scardamalia, systemic changes in the behaviour of future teachers are decisive, their experience, the development of research competence, and not scientific novelty [9]. However, the study did not note that the formation of research competence is impossible without the inclusion of this issue in the educational process. Future educators of children with MR should form research competencies not only because of internal motivation, and they should be motivated in the learning process. Teacher guidance is important to contribute during the process of teaching 
and learning; teachers can improve students' learning activity, give encouragement to seek information from various types of references such as the newspaper, magazine, encyclopedia, and internet. This process is easy for high ability students, but for lower ability students, it takes time and more planning to guide them.

Despite the relevance of research in the field of the use of modern, effective pedagogical technologies by T.V. Nefedova, scientific studies do not yet have special studies of the entire system of issues related to the representation of education as a resource for the development of the personality of schoolchildren [10]. The question of possible ways to improve the learning of students with limitations in cognitive development (mental retardation), taking into account the individual educational resources of these students, has not been studied. Also, the question of increasing the level of research skills of future teachers who will educate children with MR has not been studied. In this study, the authors show the role of the interaction of future teachers with children with inclusion in the framework of practical work. Such interaction enhances the research skills of students who are preparing to become educators.

The logic of research requires consideration of the specifics of educational research activities in comparison with design research activities on the learning parameter [11]. The pedagogical design consists of a meaningful, organisational and methodological, material-technical, and sociopsychological (emotional, communicative) design of a plan. Project activities can be organised as part of student learning, research [12-15]. The use of project activities in research provides wide opportunities for self-development and self-realisation of a student's personality [16]. But in previous studies, the component of such an activity is not indicated. The authors believe that project activities should necessarily overlap with activities that future teachers of children with disabilities will conduct in their professional environment. The interaction of participants in the educational process will help, even at the training stage, to adjust the approach of future teachers to the presentation of material and the formation of the student's personality.

Fieldwork or project work in social science is a good learning experience for students to acquire information skills and fieldwork skills to complete the given task. From these activities, they learn inquiring skills, and with discovery learning [17]. This method of learning will make learning interesting and fun for students. During the fieldwork, students foster a relationship with society. Coursework encourages students to develop their research skills, such as searching for information and new knowledge on their own or in a group. In addition, coursework gives students the opportunity to acquire various knowledge and experiences, which will become the foundation for continuous lifelong learning, as stated in the works of M. Mardis and E. Hoffman [18]. However, the studies of the mentioned authors in this question are superficial, since they do not affect the dependence of the formation of the research competence of future teachers on the component of the educational program.

\section{CONCLUSIONS}

The authors understand the research activities of students as the process of solving a creative problem that does not have a predetermined result, based on the development of the characteristics of the surrounding reality using methods of scientific work, during which cultural values are transmitted. An analysis of the psychological and pedagogical literature allows concluding that in the theory of education considerable experience has been accumulated in studying the psychological and physiological characteristics of children with MR, which confirms the individual nature of difficulties in teaching students, that creates the prerequisites for using an individualpersonal approach in their elimination and development on its basis of the skills of conducting research not only in the process of education of children with inclusion but also in the process of training teachers who will educate them.

Indicators of the formedness level of the research competence of future teachers at the final stages of the experiment significantly increased in the EG. In CG, the research competence of future teachers for all indicators increased slightly. So, the number of EG respondents with the heuristic level increased by $20.31 \%$ (in the CG by $9.02 \%$ ); by $38.28 \%$ - with a reproductive level (in the CG - by 19.67\%); the adaptive level in the EG decreased by $58.59 \%$ (in the CG - by $28.69 \%$ ). The comparative analysis of the diagnostic results of students in the experimental and control groups by the formedness of research competence before and after the experimental work allowed to conclude that in the experimental group, its formation was more effective than in control. Unfortunately, at present, there is no single understanding of the essence of research activity and 
the process of its development. This circumstance served as the basis for modelling the content of the research activities of teachers who will educate children with mental retardation. But it is an absolute fact that practical work and interaction with pupils with inclusion within the educational process of a future teacher is necessary.

\section{ACKNOWLEDGEMENTS}

None.

\section{REFERENCES}

[1] Loughran J. Teachers as leaders: building a knowledge base of practice through researching practice. In T. Townsend, R. Bates (Eds.). Handbook of Teacher Education. Dordrecht: Springer Netherlands, 2007; pp. 585-596. https://doi.org/10.1007/1-4020-4773-8 40

[2] Zhao J, Yao P, Kong J. Comparative study on international policies for teachers' ICT capacity-building. In R. Huang, Kinshuk, J.K. Price (Eds.). ICT in Education in Global Context: Comparative Reports of Innovations in K-12 Education. Berlin, Heidelberg: Springer Berlin Heidelberg 2016; pp. 267-293

https://doi.org/10.1007/978-3-662-47956-8 14

[3] Baldwin MD, Keating JF. Innovative team building practices for professionals: developing inter-group skills to enhance effective performance. Innovative Higher Education 1998; 22(4): 291-309.

https://doi.org/10.1023/A:1025149424436

[4] Vandyck I, de Graaff R, Pilot A, Beishuizen J. Community building of (student) teachers and a teacher educator in a school - university partnership. Learning Environments Research 2012; 15(3): 299-318.

https://doi.org/10.1007/s10984-012-9118-2

[5] Tan SC, Cheah HM, Chen W, Choy D. Capacity building of school leaders and teachers. In Pushing the Frontier: A Cohesive System-wide Approach to Integrating ICT into Education. Singapore: Springer Singapore, 2017; pp. 57-72. https://doi.org/10.1007/978-981-10-4239-3 5

[6] Abolin LM. Teacher in the modern educational space. Kazan: Taglimat, 1999.

[7] Andreev ID. Ways to improve the effectiveness of scientific work. Moscow: Nauka, 1980

[8] Finlayson OE, McLoughlin E. Building teacher confidence in inquiry and assessment: experiences from a Pan-European collaboration. In M.A. Peters, B. Cowie, I. Menter (Eds.). A Companion to Research in Teacher Education. Singapore: Springer Singapore, 2017; pp. 825-838 https://doi.org/10.1007/978-981-10-4075-7 56
[9]

Scardamalia M, Bransford J, Kozma B, Quellmalz E. New assessments and environments for knowledge building. In $\mathrm{P}$. Griffin, B. McGaw, E. Care (Eds.). Assessment and Teaching of 21st Century Skills. Dordrecht: Springer Netherlands, 2012; pp. 231-300 https://doi.org/10.1007/978-94-007-2324-5 5

[10] Nefedova TV. Motivation as a condition for the development of cognitive activity of students with disabilities. Cheboksary: Research Institute of Pedagogy and Psychology 2011.

[11] Li Q. Enactivism and teacher instructional game building: an inquiry of theory adoption and design consideration. Educational Technology Research and Development 2018; 66(6): 1339-1358.

https://doi.org/10.1007/s11423-018-9584-z

[12] Darling-Hammond L. Building a profession of teaching. In M.A. Flores, A.A. Carvalho, F.I. Ferreira, M.T. Vilaça (Eds.). Back to the Future: Legacies, Continuities and Changes in Educational Policy, Practice and Research. Rotterdam: Sense Publishers, 2013; pp. 3-27 https://doi.org/10.1007/978-94-6209-240-2 1

[13] Heffernan NT, Heffernan CL. The ASSISTments ecosystem: building a platform that brings scientists and teachers together for minimally invasive research on human learning and teaching. International Journal of Artificial Intelligence in Education 2014; 24(4): 470-497.

https://doi.org/10.1007/s40593-014-0024-x

[14] Hopkins S, Round P. Building stronger teacher education programmes to prepare inclusive teachers. In A. Fitzgerald, G. Parr, J. Williams (Eds.). Re-imagining Professional Experience in Initial Teacher Education: Narratives of Learning. Singapore: Springer Singapore, 2018; pp. 55-66 https://doi.org/10.1007/978-981-13-0815-4_4

[15] Ovando MN. Building instructional leaders' capacity to deliver constructive feedback to teachers. Journal of Personnel Evaluation in Education 2005; 18(3): 171-183. https://doi.org/10.1007/s11092-006-9018-z

[16] Freeman, E., and Strong, D. Building teacher capacity to promote social and emotional learning in Australia. In E. Frydenberg, A.J. Martin, R.J. Collie (Eds.). Social and Emotional Learning in Australia and the Asia-Pacific: Perspectives, Programs and Approaches. Singapore: Springer Singapore, 2017; pp. 413-435. https://doi.org/10.1007/978-981-10-3394-0 22

[17] Smith K, Lindsay S. Building future directions for teacher learning in science education. Research in Science Education 2016; 46(2): 243-261. https://doi.org/10.1007/s11165-015-9510-x

[18] Mardis M, Hoffman E. Building digital libraries for children: reviewing information literacy of students and teachers. In E.P. Lim, S. Foo, C. Khoo, H. Chen, E. Fox, S. Urs, T. Costantino (Eds.). Digital Libraries: People, Knowledge, and Technology. Berlin, Heidelberg: Springer Berlin Heidelberg 2002; pp. 404-405.

https://doi.org/10.1007/3-540-36227-4_45

Received on 25-07-2020

Accepted on 19-08-2020

Published on 14-09-2020

\section{DOI: https://doi.org/10.6000/2292-2598.2020.08.03.18}

(C) 2020 Beisenbayeva et al.; Licensee Lifescience Global.

This is an open access article licensed under the terms of the Creative Commons Attribution Non-Commercial License (http://creativecommons.org/licenses/by-nc/3.0/) which permits unrestricted, non-commercial use, distribution and reproduction in any medium, provided the work is properly cited. 